\title{
Degradation of Sulfated Proteoglycans in the Subendothelial Extracellular Matrix by Human Platelet Heparitinase
}

\author{
Joachim Yahalom, Amiram Eldor, \\ Zvi Fuks, and Israel Vlodavsky \\ Department of Radiation and Clinical Oncology, Department of \\ Hematology, Hadassah University Hospital, Jerusalem, Israel
}

bstract. Cultured vascular and corneal endothelial cells produce an underlying extracellular matrix (ECM) which induces platelet adherence, aggregation, and release reaction. Incubation of a metabolically $\left.{ }^{35} \mathrm{~S}\right) \mathrm{O}_{4}^{=}$-labeled ECM with platelet-rich plasma or washed platelets, but not with platelet-poor plasma, resulted in degradation of its heparan sulfate-containing proteoglycans into labeled fragments four to five times smaller than intact glycosaminoglycan side chains. These fragments were sensitive to deamination with nitrous acid and were not produced in the presence of heparin, indicating that heparan sulfate in the ECM is susceptible to cleavage by the platelet heparitinase. This degradation required adhesion of platelets to the ECM rather than aggregation since it was not inhibited by aspirin, which prevented platelet aggregation but not adherence. The enzyme was not released during aggregation of platelets on the ECM but was readily liberated upon their exposure to thrombin. This liberation was inhibited in the presence of prostacyclin $\left(\mathrm{PGI}_{2}\right)$. Isolated high molecular weight proteoglycans first released from the ECM by incubation with platelet poor plasma served as a substrate for further degradation by the platelet heparitinase, suggesting a cascade mechanism for degradation of heparan sulfate in the ECM. Heparitinase, although to a lower level, was also active when washed platelets were added on top of a confluent endothelial cell monolayer covering the $\left({ }^{35} \mathrm{~S}\right) \mathrm{O}_{4}^{=}$-labeled ECM. It is suggested that the platelet heparitinase may be involved in the impairment of the

\footnotetext{
Address correspondence to Dr. Vlodavsky.

Received for publication 17 October 1983 and in revised form 12 July 1984.
}

J. Clin. Invest.

(C) The American Society for Clinical Investigation, Inc. 0021-9738/84/11/1842/08 \$1.00

Volume 74, November 1984, 1842-1849 integrity of the vessel wall and thus facilitate the extravasation of blood-borne cells.

\section{Introduction}

A heparan sulfate-degrading enzyme (heparitinase) has been characterized and purified from human platelets (1-4). The enzyme was shown to be a lysosomal endoglycosidase which hydrolizes glucuronsyl-glucosamine linkages (4). Heparin-like molecules liberated during its activity on the vascular endothelium were shown to inhibit smooth muscle cell proliferation, and thus, this suggests that the platelet heparitinase is involved in the process of vascular repair (5). Due to its lysosomal localization, liberation of the enzyme requires concentration of agonists above those necessary to induce $\alpha$-granule release (5). Therefore, it has been more readily liberated with thrombin or collagen than with adrenaline or ADP (4).

We have recently reported on the use of the extracellular matrix $(\mathrm{ECM})^{1}$ produced by cultured bovine endothelial cells as a model to study the interaction of platelets with the subendothelium in vivo (6). This ECM was shown to closely resemble the vascular basal lamina in its organization and supramolecular structure, and to contain characteristic components of basement membranes such as type IV and V collagen, laminin, fibronectin, and heparan sulfate (7-9). The ECM was found to induce platelet adhesion, aggregation, thromboxane $A_{2}$ formation, and release reaction in a manner similar to that observed in vivo (6). Metabolic labeling of the endothelial cell cultures with $\mathrm{Na}_{2}\left({ }^{35} \mathrm{~S}\right) \mathrm{O}_{4}$ resulted in a specific labeling of sulfated glycosaminoglycans in the ECM $(9,10)$. Since heparan sulfate is a major constituent of this subendothelial $\operatorname{ECM}(11,12)$, we used labeled ECM to investigate the requirements for heparan sulfate degradation by human platelet heparitinase. Our data show that heparan sulfate in the ECM is indeed available for degradation by platelet heparitinase and

1. Abbreviations used in this paper: CPC, cetyl pyridinium chloride; ECM, extracellular matrix; FGF, fibroblast growth factor; Kav, K available; $\mathrm{PGI}_{2}$, prostacyclin; PPP, platelet-poor plasma; PRP, plateletrich plasma. 
that adhesion rather than aggregation is required for the expression of its activity. Degradation occurred, but to a much smaller extent, when platelets were added on top of a confluent endothelial cell monolayer covering the labeled ECM.

\section{Methods}

Materials. Fibroblast growth factor (FGF) was purified from bovine brain as previously described (13). Dulbecco's modified Eagle's medium H-16, calf serum, fetal calf serum, penicillin, streptomycin, and trypsin/ EDTA solution were obtained from Gibco Laboratories (Grand Island, NY). Tissue culture dishes were purchased from Falcon Labware, Becton-Dickinson Co. (Oxnard, CA). Triton X-100 and dextran T-40 were obtained from Sigma Chemical Co. (St. Louis, MO). Gentamicin was from Schering $\mathrm{Co}$. (Kenilworth, $\mathrm{NJ}$ ). $\mathrm{Na}_{2}{ }^{35} \mathrm{SO}_{4}$ and Biofluor scintillation fluid were obtained from New England Nuclear (Boston, MA) and Sepharose 6B from Pharmacia Fine Chemicals (Uppsala, Sweden). Prostacyclin $\left(\mathrm{PGI}_{2}\right)$ was kindly provided by Dr. J. Pike, Upjohn Co. (Kalamazoo, MI). All other chemicals were of reagent grade purchased from Sigma Chemical Co.

Preparation of platelet-rich plasma (PRP). Blood from healthy individuals who had a history of no drug ingestion for at least $10 \mathrm{~d}$ before testing was obtained by venipuncture with the two-syringe technique and mixed with 0.1 vol of $3.2 \%$ trisodium citrate (6). PRP was prepared by centrifugation at $150 \mathrm{~g}$ for $10 \mathrm{~min}$ at room temperature (6). This preparation yielded a concentration of $2-3 \times 10^{5}$ platelets $/ \mu 1$ as determined by counting with a Coulter Counter (Coulter Electronics, Hialeah, FL). Platelet-poor plasma (PPP) was prepared by centrifugation of PRP ( $1 \mathrm{~min}, 10,000 \mathrm{~g}$ ), followed by a second centrifugation of the supernatant at a $10,000 \mathrm{~g}$ for $5 \mathrm{~min}$ (Eppendorf model 5414). The resultant PPP contained $<3,000$ platelets $/ \mu$ l. Washed platelets were prepared in tyrode buffer in the presence of $P E_{1}$ as described (14). SEM studies have verified the discoid nature of the washed platelets.

Bovine endothelial cells. Clonal populations of bovine vascular endothelial cells derived from the adult aortic arch were obtained as previously described (15). Cells were routinely cultured in Dulbecco's modified Eagle's medium $\mathrm{H} 16$ supplemented with $10 \%$ calf serum and gentamicin $(50 \mu \mathrm{g} / \mathrm{ml})$ at $37^{\circ} \mathrm{C}$ in $10 \% \mathrm{CO}_{2}$ humidified incubators. Cells were subcultured weekly with $0.05 \%$ trypsin $/ 0.02 \%$ EDTA solution and FGF $(100 \mathrm{ng} / \mathrm{ml})$ was added every other day during the phase of active cell growth. Confluent cultures composed of flattened, closely apposed, and nonoverlapping cells were kept without further addition of FGF. Cultures of bovine corneal endothelial cells were established from steer eyes as described (16) and stock cultures maintained as in the case of vascular cells, except that $5 \%$ fetal calf serum was included in the growth medium.

Preparation of dishes coated with ECM. Vascular or corneal endothelial cells were plated at an initial density of $4 \times 10^{4}$ cells/35-mm dish and maintained under the same conditions described above except that 5\% dextran T-40 was also included in the growth medium. 6-8 d after reaching confluency, the cell layer was dissolved with $0.5 \%$ Triton $\mathrm{X}-100$ as previously described $(7,8)$, leaving the underlying ECM intact and firmly attached to the entire tissue culture dish. Remaining nuclei and cytoskeletons were removed by a 2-3 min exposure to $0.025 \mathrm{~N} \mathrm{NH}_{4} \mathrm{OH}$ followed by four washes with phosphatebuffered saline (PBS). Some of the ECM-coated dishes were purchased from International Biotechnology Ltd, Hadassah, Jerusalem, Israel.

Degradation of sulfated proteoglycans. Subconfluent cultures of bovine endothelial cells were metabolically labeled with $\mathrm{Na}_{2}\left({ }^{35} \mathrm{~S}\right) \mathrm{O}_{4}$ ( $540-590 \mathrm{mCi} / \mathrm{mmol})$ added to the growth medium on days 4 and 8 after seeding ( $40 \mu \mathrm{Ci} / \mathrm{ml}$ each time). Cultures were incubated with the radiolabeled sulfate without medium change, followed by solubilization of the cell layer, $8 \mathrm{~d}$ after reaching confluency, and preparation of dishes coated with $\left({ }^{35} \mathrm{~S}\right) \mathrm{O}_{4}^{=}$-labeled ECM, as previously described (10).

PRP or PPP $(1 \mathrm{ml})$ were incubated with the labeled ECM at $37^{\circ} \mathrm{C}$ in $10 \% \mathrm{CO}_{2}$ humidified incubators. The supernate was collected after $24 \mathrm{~h}$ (except when tested at shorter intervals), centrifuged at $10,000 \mathrm{~g}$ for $5 \mathrm{~min}$, and $0.5-0.7 \mathrm{ml}$ aliquots applied for gel filtration on Sepharose $6 \mathrm{~B}$ columns $(0.7 \times 35 \mathrm{~cm}$ in most experiments and $1.1 \times 70 \mathrm{~cm}$ in some experiments). Samples were eluted with PBS, and $0.2-\mathrm{ml}$ fractions were collected at a flow rate of $5 \mathrm{ml} / \mathrm{h}$ and taken for radioactive counting using Biofluor scintillation fluid. The excluded volume, $\mathrm{V}_{0}$, was marked by blue dextran and the total included volume, $V_{t}$, by phenol red. The latter was shown to comigrate with free $\left({ }^{35} \mathrm{~S}\right) \mathrm{O}_{4}^{-}$. Similar results were obtained by using the ECM produced by either corneal or vascular bovine endothelial cells and whether the centrifuged media were subjected to gel filtration under dissociation conditions (4 M guanidine- $\mathrm{HCl}$ in $0.1 \mathrm{M}$ sodium acetate, $\mathrm{pH} 5.5$ ) or eluted with PBS (10). Recoveries of incorporated radioactivity applied on the columns ranged from 85 to $95 \%$ in different experiments. Each experiment was performed at least four times and the variation in elution positions ( $\mathrm{K}$ available [Kav] values) was $<10 \%$.

\section{Results}

Degradation of sulfated proteoglycans in the ECM by platelet heparitinase. To test whether the interaction of human platelets with the ECM is associated with degradation of proteoglycans by the platelet heparitinase, PPP and PRP were incubated with $\left({ }^{35} \mathrm{~S}\right) \mathrm{O}_{4}^{=}$-labeled ECM followed by gel filtration (Sepharose 6B) analysis of the degradation products released into the incubation medium. The $\mathrm{pH}$ of the PPP or PRP was first adjusted to $\mathrm{pH} 6.5$, since it was previously shown that heparitinase activity is low at $\mathrm{pH}$ exceeding 7.2 (1). Incubation of the labeled ECM with PPP resulted in a release of high $M_{\mathrm{r}}$ degradation products as demonstrated by $>90 \%$ of the released radioactivity eluted with or next to $\mathrm{V}_{0}$ (fraction 13-28, peak I) (Fig. $1 \mathrm{~A}$ ). This material comigrated with dextran blue on Sepharose 2B $(\mathrm{Kav}=0.51)$, and showed an elution profile similar to the $\sim 10^{6}$-D sulfated proteoglycans released from the ECM upon incubation with culture medium alone $(9,10)$ or by a short exposure of the ECM to trypsin (17). In contrast, incubation of the labeled ECM with PRP was associated with a release of radioactive material that eluted with a $\mathrm{Kav}=0.63$ (fractions $25-45$, peak II) and constituted $\sim 80 \%$ of the total released radioactivity (Fig. $1 A$ ). Based on the observed Kav value and the migration of chondroitin sulfate fractions of known $M_{\mathrm{r}}$, it can be estimated that the ${ }^{35} \mathrm{~S}$-labeled material eluted in peak II had a $M_{\mathrm{r}}$ of about $10,000 \mathrm{D}$ (18). In contrast, when the interaction of PRP with ECM was tested at pH 7.4, mostly high $M_{\mathrm{r}}$ fragments were released (peak I), reflecting the pH dependency of the enzyme (Fig. $1 B$ ).

The effect of platelet concentration and incubation time on the release of material eluted in peak II was studied. For 

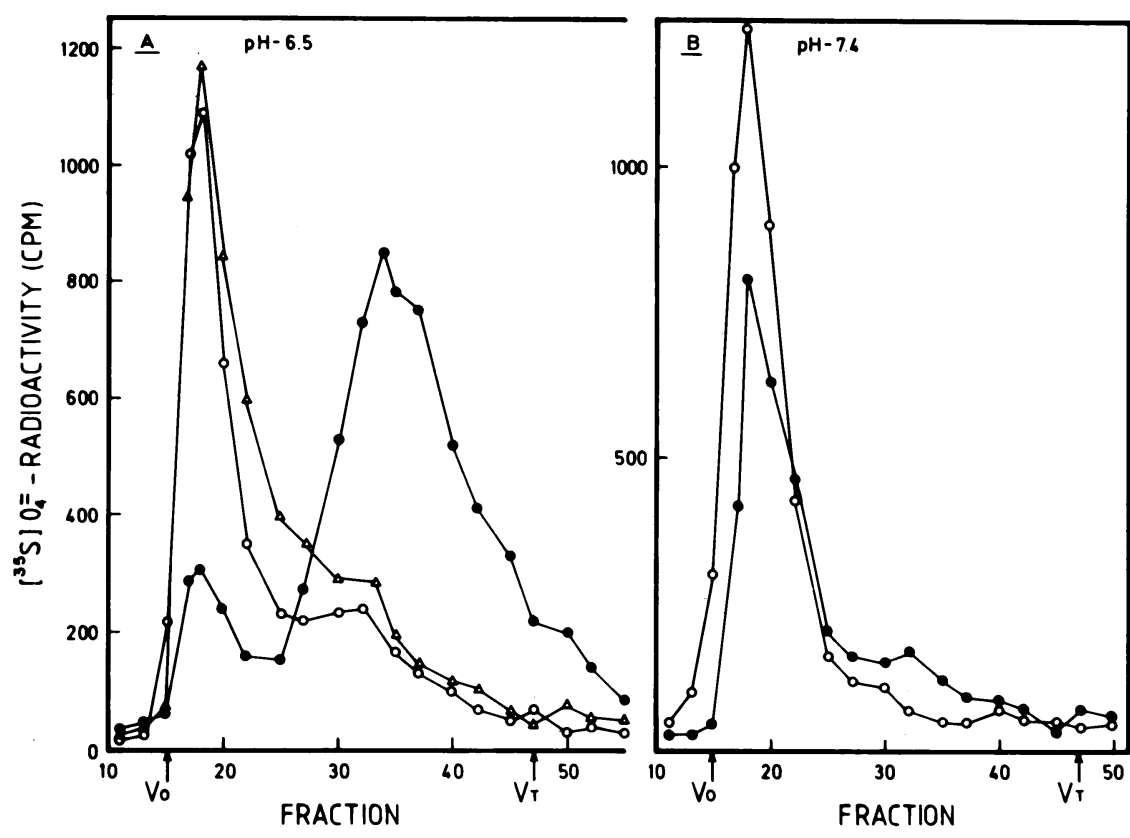

Figure 1. Degradation of $\left({ }^{35} \mathrm{~S} \mathrm{O}_{4}=\right.$-labeled ECM by PRP and PPP. $1 \mathrm{ml}$ PRP (๑) or PPP (O) were incubated $\left(24 \mathrm{~h}, 37^{\circ} \mathrm{C}\right)$ on top of $\left({ }^{35} \mathrm{~S}^{\circ} \mathrm{O}_{4}^{-}\right.$-labeled $\mathrm{ECM}$ with $(A)$ or without $(B)$ preadjustment of the $\mathrm{pH}$ to 6.5. Labeled ECM was also incubated with PRP ( $\mathrm{pH} 6.5$ ) in the presence of $10 \mu \mathrm{g} / \mathrm{ml}$ heparin $(\Delta)$. The PRP and PPP were then centrifuged and the supernatant taken for separation by gel filtration on Sepharose 6B, as described under Methods. this purpose PRP was diluted with PPP to yield varying concentrations of platelets. These were incubated $\left(24 \mathrm{~h}, 37^{\circ} \mathrm{C}\right)$ with the labeled ECM and the amount of released radioactivity eluted as peak II calculated and plotted as a function of platelet number (Fig. $2 A$ ). When the ratio of counts per minute eluted as peak II to that eluted as peak I was calculated, it was found that whereas PPP alone yielded a ratio $<0.25$ and the undiluted PRP gave a ratio $>30$, PRP diluted to a platelet count of only $8 \times 10^{3}$ platelets $/ \mu$ l yielded a second peak which was four times greater than the first peak. Enzymatic degradation manifested by the appearance of peak II was already observed after $3 \mathrm{~h}$ of incubation and reached a maximal value at $24 \mathrm{~h}$ (Fig. $2 \mathrm{~B}$ ). Similar experiments with washed platelet suspensions also showed a release of the low $M_{\mathrm{r}}$ degradation products (peak II), indicating that the platelet heparitinase was active also in the absence of plasma components (Fig. 3).

To further identify the nature of degradation products eluted in peak II, the size of intact glycosaminoglycan side chains was determined by subjecting the ECM to papain digestion $\left(0.2 \mathrm{mg} / \mathrm{ml}, 24 \mathrm{~h}, 50^{\circ} \mathrm{C}\right)$ or to cleavage with alkaline borohydride (1 $\mathrm{M} \mathrm{NaBH}_{4}$ in $\left.0.05 \mathrm{~N} \mathrm{NaOH}, 24 \mathrm{~h}, 45^{\circ} \mathrm{C}\right)(9$, 10). The results demonstrated that radioactive material released by both procedures was eluted with a Kav of $\sim 0.3$ from a Sepharose 6B column. This value corresponds to a $M_{\mathrm{r}}$ of $\sim 45,000 \mathrm{D}$, which is four- to fivefold higher than that of
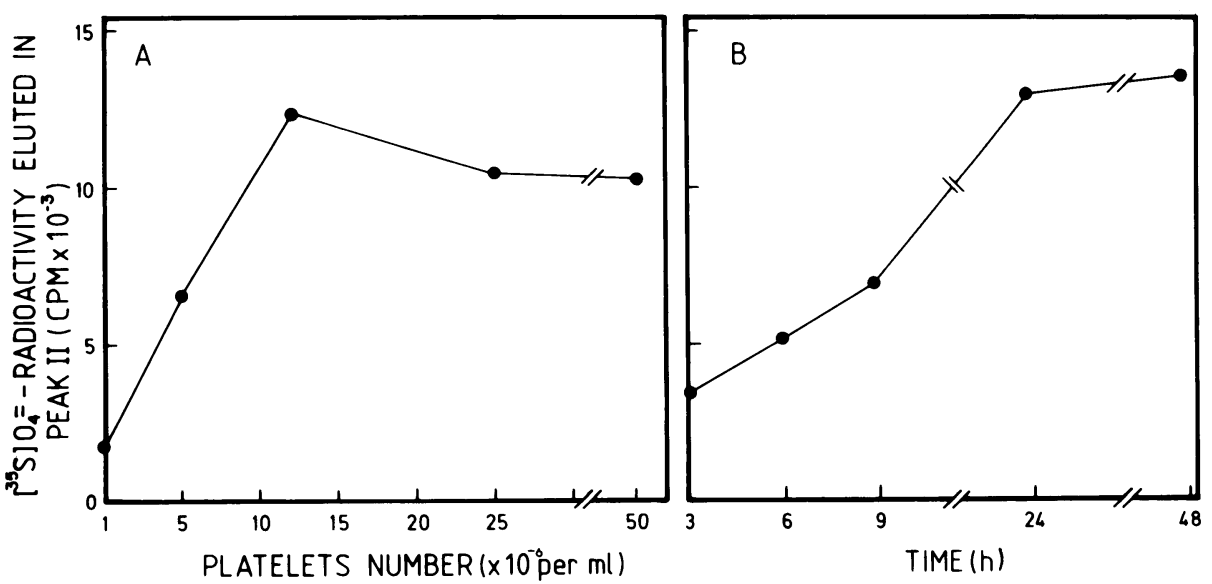

Figure 2. Degradation of $\left.{ }^{35} \mathrm{~S}\right) \mathrm{O}_{4}^{=}$-labeled ECM as a function of platelet number and incubation time. $(A)$ PRP was diluted with PPP to yield different concentrations of platelets. $1 \mathrm{ml}$ of the various dilutions were incubated $(24 \mathrm{~h}$ at $37^{\circ} \mathrm{C}, \mathrm{pH} 6.5$ ) with the labeled ECM, subjected to gel filtration (Sepharose 6B), and the total amount of radioactivity eluted in peak II (sum of cpm eluted in fractions 25-45) plotted against the approximate number of platelets. $(B) 1 \mathrm{ml}$ of PRP was incubated $\left(37^{\circ} \mathrm{C}, \mathrm{pH} 6.5\right)$ with the labeled ECM and the total amount of released radioactivity eluted as peak II (sum of cpm eluted in fractions 25-45) is plotted as a function of the incubation time. 


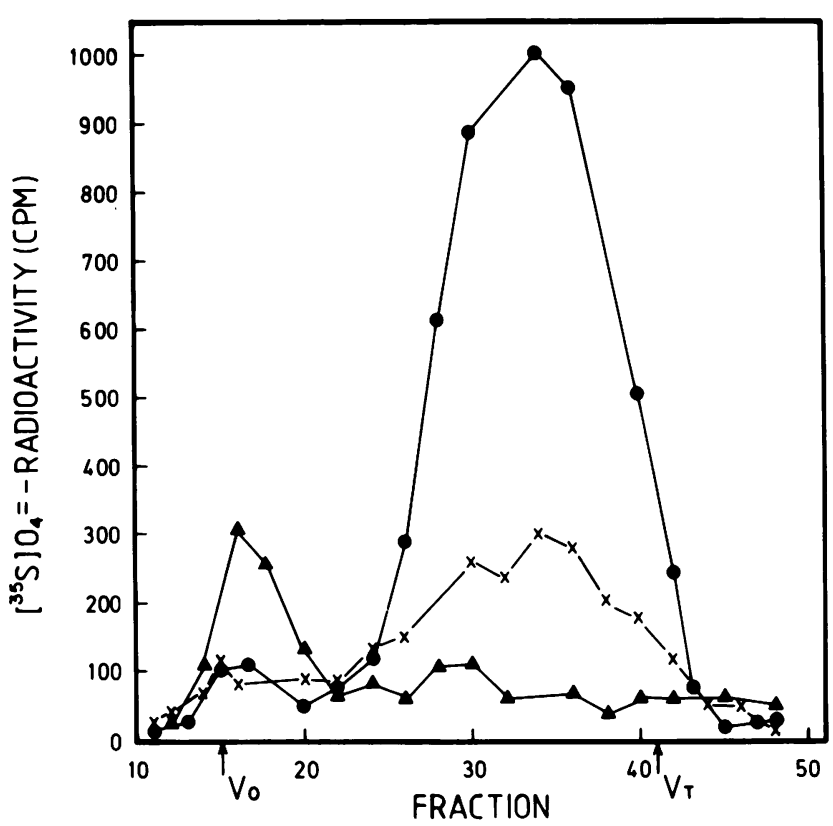

Figure 3. Degradation of sulfated proteoglycans by washed platelets incubated with ${ }^{35} \mathrm{~S}^{3} \mathrm{O}_{4}^{-}$-labeled ECM when either exposed or covered with a confluent endothelial cell monolayer. Platelets were washed in tyrode buffer as described (14), suspended in RPMI mediam, $\mathrm{pH} 6.8$ and incubated $\left(24 \mathrm{~h}, 37^{\circ} \mathrm{C}\right)$ with an exposed ECM $(\bullet)$ or on top of a confluent endothelial cell monolayer covering the labeled ECM $(x)$.

Culture dishes containing endothelial cell monolayers but no platelets (₫) were incubated under the same conditions. The medium was collected, centrifuged, and analyzed by gel filtration on Sepharose 6B.

fragments released upon incubation of the ECM with PRP $(\mathrm{Kav}=0.63)$. Degradation products eluted in peak II were precipitated with $1 \%$ cetyl pyridinium chloride (CPC) in 0.05 $\mathrm{M} \mathrm{NaCl}(18,19)$ and were resistant to further digestion with papain or chondroitinase ABC. Previous studies have shown that $\sim 70 \%$ of the $\left({ }^{35} \mathrm{~S}\right) \mathrm{O}_{4}^{=}$radioactivity in the labeled ECM is incorporated into the glycosaminoglycan moieties of heparan sulfate (9). Up to $90 \%$ of the total labeled heparan sulfate proteoglycan was released into the incubation medium, and $80-90 \%$ of this radioactivity was degraded into fragments eluted as peak II upon incubation of the ECM with $1 \mathrm{ml}$ PRP for $24 \mathrm{~h}$. A lower percentage of released material was obtained under less adequate incubation conditions (platelet concentration, incubation times, $\mathrm{pH}$ ). That the low $M_{\mathrm{r}}$ degradation products released by platelets were indeed fragments of heparan sulfate side chains was proven by their sensitivity to deamination with nitrous acid $(20,21)$. Exposure of the labeled material eluted as peak II to nitrous acid $\left(0.24 \mathrm{M} \mathrm{NaNO}_{3}\right.$ in $1.8 \mathrm{M}$ acetic acid, $\left.80 \mathrm{~min}, 24^{\circ} \mathrm{C}\right)(20)$ resulted in its conversion to low $M_{\mathrm{r}}\left(\sim 2.5 \times 10^{3} \mathrm{D}\right)$ fragments which were not precipitated by $\mathrm{CPC}$, were eluted with a $\mathrm{Kav}=0.84$ when applied onto Sepharose 6B, and were retarded on Sephadex G-50. Furthermore, $75 \%$ of the radioactivity in peak II was precipitated with
CPC under conditions $(0.05 \% \mathrm{CPC}$ in $0.6 \mathrm{M} \mathrm{NaCl})$ that have been shown to specifically precipitate heparan sulfate sequences (19). These results were further verified by showing that the platelet endoglycosidase activity was entirely blocked by heparin (Fig. $1 A$ ). In the presence of heparin, all the radioactivity released from the ECM by PRP was in the form of high $M_{\mathrm{r}}$ material eluted with or next to the $\mathrm{V}_{0}$ (Fig. $1 A$ ). Heparin did not affect the release of $\left({ }^{35} \mathrm{~S}\right) \mathrm{O}_{4}^{=}$-labeled material (peak I) during incubation of the ECM with PPP. Various protease inhibitors ( $5 \mathrm{mM}$ diisopropylfluorophosphate, $5 \mu \mathrm{g} / \mathrm{ml}$ leupeptin, $5 \mathrm{mM}$ phenylmethylsulfonylfluoride, $50 \mu \mathrm{g} / \mathrm{ml}$ soybean trypsin inhibitor) failed to inhibit the release of both the high (peak I) and low (peak II) $M_{\mathrm{r}}$ sulfate-labeled components when added alone or in various combinations.

Release of heparitinase activity by thrombin and its inhibition by $\mathrm{PGI}_{2}$. It has been shown that thrombin induces release of platelets $\alpha$-granules components (22). Fig. $4 A$ shows that incubation of ECM with supernatants obtained from thrombin-treated PRP ( $1 \mathrm{unit} / \mathrm{ml}, 2 \mathrm{~min}, 37^{\circ} \mathrm{C}$ ) resulted in the release of the low $M_{\mathrm{r}}$ degradation products eluted in peak II, reflecting the liberation of the platelet heparitinase. In contrast, thrombin-treated PPP did not exhibit any heparan sulfate-degrading activity. When PRP was treated with thrombin in the presence of $1 \mathrm{ng} / \mathrm{ml} \mathrm{PGI}$, almost no peak II radioactivity was released upon incubation of the resulting serum with the labeled ECM. A similar effect but to a somewhat lower extent was obtained with a lower concentration of $\mathrm{PGI}_{2}(0.05 \mathrm{ng} / \mathrm{ml}$, Fig. 4). These results indicate that the thrombin-mediated release of the platelet heparitinase was inhibited in the presence of $\mathrm{PGI}_{2}$.

Platelet heparitinase activity does not require platelet aggregation. We have previously shown that aspirin-treated platelets adhere but do not aggregate when incubated with the ECM (6). Incubation of labeled ECM with aspirin-treated PRP was associated with degradation of the ECM in a manner similar to that of untreated PRP, indicating that platelet aggregation per se is not necessary for the expression of heparitinase activity. This result was further supported by the observation that washed platelets degraded heparan sulfate in the ECM (Fig. 3) despite their inability to undergo aggregation in the absence of added fibrinogen (Eldor, A., I. Vlodavsky, Z. Fuks, and B. S. Coller, manuscript submitted for publication).

To study whether aggregation of platelets during incubation with ECM can induce the release of heparitinase, PRP was allowed to undergo aggregation by incubation $\left(4 \mathrm{~h}, 37^{\circ} \mathrm{C}\right.$ with gentle shaking) with unlabeled ECM at pH 7.4. The supernate fraction was centrifuged $(1 \mathrm{~min}, 10,000 \mathrm{~g})$ and the resulting PPP adjusted to pH 6.5 and incubated $\left(24 \mathrm{~h}, 37^{\circ} \mathrm{C}\right)$ with $\left({ }^{35} \mathrm{~S} \mathrm{O}_{4}^{=}\right.$-labeled ECM. Fig. 5 demonstrates that the supernatant collected after platelet aggregation on unlabeled ECM showed no heparitinase activity. In contrast, when the remaining platelet aggregates were mechanically disrupted and removed for incubation with the labeled ECM, enzymatic activity was recovered as evidenced by release of heparan sulfate degradation 


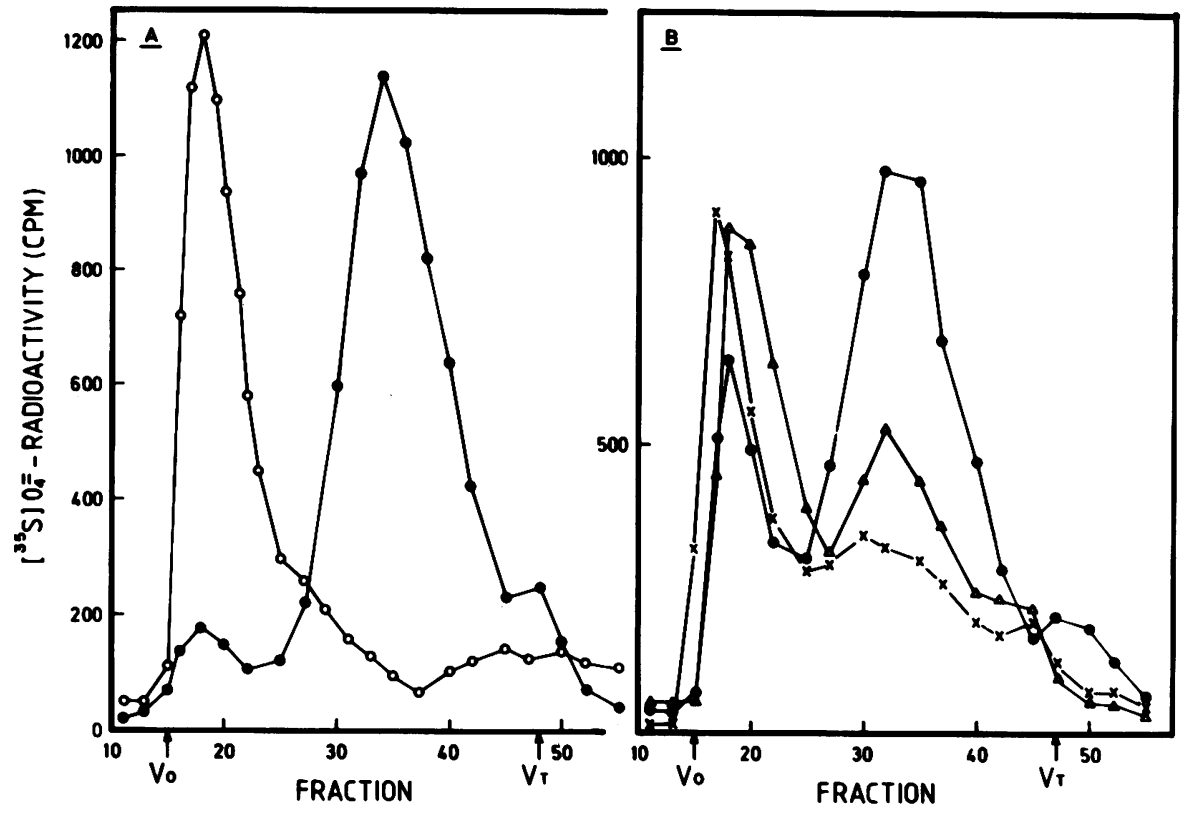

Figure 4. Release of platelet heparitinase by thrombin and its inhibition by $\mathrm{PGI}_{2}$. $(A)$ PRP $(\bullet)$ and PPP (O) were treated $\left(30 \mathrm{~min}, 37^{\circ} \mathrm{C}\right)$ with thrombin ( 1 unit/ml). $1 \mathrm{ml}$ of the serum obtained after centrifugation was incubated $\left(24 \mathrm{~h}, 37^{\circ} \mathrm{C}, \mathrm{pH}\right.$ 6.5 ) with the labeled ECM and subjected to gel filtration on Sepharose 6B. (B) PRP was treated ( $2 \mathrm{~min}$, $37^{\circ} \mathrm{C}$ ) with thrombin $(1 \mathrm{unit} / \mathrm{ml})$ in the absence $(\bullet)$ and presence of 1 $\mathrm{ng} / \mathrm{ml}(x)$ or $0.05 \mathrm{ng} / \mathrm{ml}(\Delta) \mathrm{PGI}_{2}$. 1 $\mathrm{ml}$ of the serum obtained after centrifugation was incubated $(24 \mathrm{~h}$, $\left.37^{\circ} \mathrm{C}, \mathrm{pH} 6.5\right)$ with $\left({ }^{35} \mathrm{~S}\right) \mathrm{O}_{4}^{-}$-labeled ECM and analyzed by gel filtration as described under Methods. fragments (Fig. 5). Despite the lack of heparitinase release, the ECM-induced aggregation of platelets was associated with both serotonin release and thromboxane $A_{2}$ synthesis $(32 \mathrm{ng} / \mathrm{ml})$ (6), albeit to a lower extent that that observed in the presence of thrombin.

Degradation of high $M_{\mathrm{r}}$ proteoglycans eluted in peak $I$ by platelet heparitinase. We have previously shown that the high $M_{\mathrm{r}}\left({ }^{35} \mathrm{~S}\right) \mathrm{O}_{4}^{-}$-labeled material eluted in peak I can serve as a substrate for further degradation by a heparan sulfate endoglycosidase secreted by highly metastatic mouse lymphoma cells (10). Sulfate-labeled peak I material was obtained by incubation of the ECM with PPP, collected, and incubated $\left(24 \mathrm{~h}, 37^{\circ} \mathrm{C}\right.$ ) at pH 6.5 with either PRP (Fig. 6) or with supernatant obtained from thrombin-treated PRP. The results (Fig. 6) show that the platelet heparitinase degraded the peak I material into low $M_{\mathrm{r}}$-labeled components similar in size to peak II products. A similar incubation with PPP did not result in such enzymatic cleavage.

Interaction of platelets with ECM covered by a confluent endothelial cell monolayer. Since in vivo the vascular endothelium protects the vessel wall against platelet deposition, we tested the capacity of platelets to degrade the subendothelial proteoglycans when the labeled ECM was entirely covered with endothelial cells. Metabolically $\left({ }^{35} \mathrm{~S}\right) \mathrm{O}_{4}^{-}$-labeled ECM was prepared and covered with a confluent bovine aortic endothelial cell monolayer as described in Methods. The medium was replaced with serum-free medium, washed platelets were added, and $24 \mathrm{~h}$ later, the medium was collected and analyzed for the appearance of labeled degradation products. The elution profile on Sepharose $6 \mathrm{~B}$ showed that $>90 \%$ of the released radioactive material was eluted as peak II (Fig. 3). However, the total released radioactivity was about fivefold lower than that released by washed platelets incubated in direct contact with an exposed ECM (Fig. 3). Control cultures of endothelial cells similarly incubated without platelets failed to release low $M_{\mathrm{r}}$ labeled components eluted as peak II.

\section{Discussion}

We have previously reported that the subendothelial ECM induces rapid and massive platelet adherence, aggregation, thromboxane synthesis, and release reaction (6). The present study demonstrates that interaction of platelets with the ECM also resulted in degradation of sulfated proteoglycans into fragments four to five times smaller than its intact glycosaminoglycan side chains. The fact that these degradation products contain heparan sulfate species was demonstrated by their sensitivity to cleavage with nitrous acid and precipitation with $0.05 \% \mathrm{CPC}$ in $0.6 \mathrm{M} \mathrm{NaCl}(19-21)$. This was further supported by the complete inhibition of degradation in the presence of heparin.

Platelet heparan sulfate endoglycosidase (heparitinase) was first identified by Wasteson et al. $(1,2)$ and was recently purified and characterized $(3,4)$. In these studies, the enzyme activity was demonstrated and assessed using heparin or heparan sulfate, either soluble or bound to Sepharose, as substrates (1-4). Our results indicate that heparan sulfate, which is the major sulfated proteoglycan in naturally occurring basement membranes $(11,12)$, is available for degradation by the platelet heparitinase also when found in a complex structure such as the ECM. Although our data are semiquantitative and cannot be treated as an ordinary enzyme assay, they clearly indicate that neither the supramolecular structure of the ECM, nor other components of the vascular basement membrane (23), prevent the interaction of the platelet heparitinase with sulfated proteoglycans in the subendothelium. Therefore, these results 


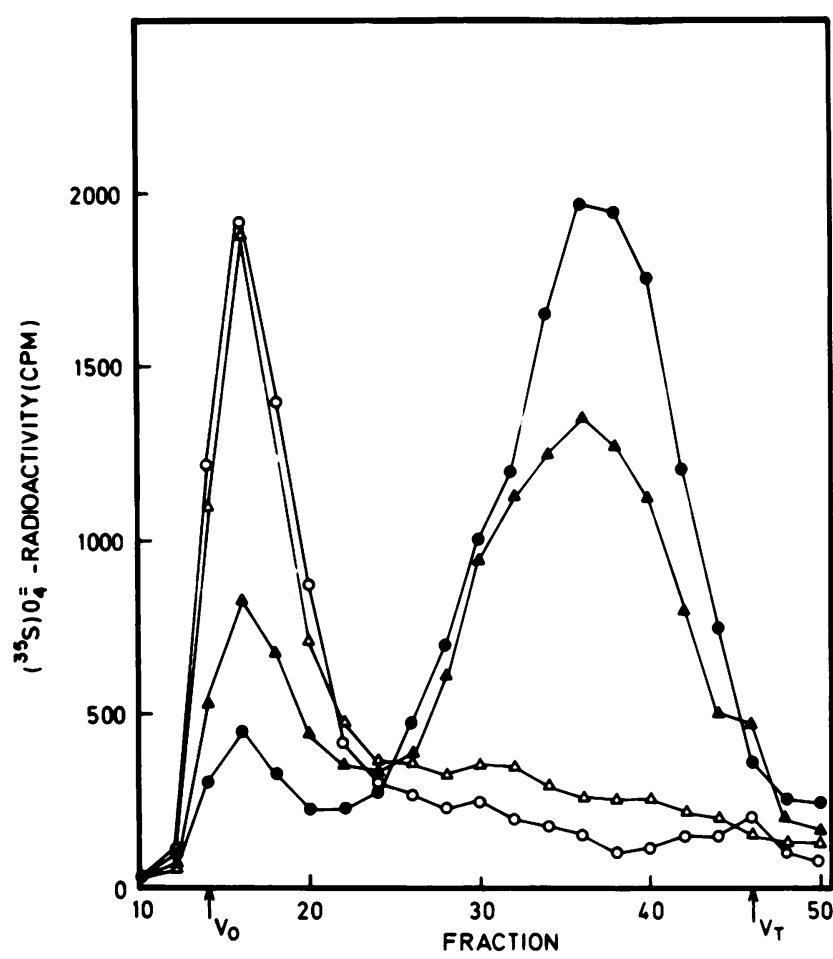

Figure 5. Effect of ECM-induced platelet aggregation on heparitinase release. $1 \mathrm{ml} \mathrm{PRP}$ was incubated $\left(4 \mathrm{~h}, 37^{\circ} \mathrm{C}\right.$, gentle shaking) on top of unlabeled ECM to induce platelet aggregation. The plasma was then collected and centrifuged $(150 \mathrm{~g} \times 10 \mathrm{~min})$, and the supernate fraction was adjusted to $\mathrm{pH} 6.5$ and incubated $\left(24 \mathrm{~h}, 37^{\circ} \mathrm{C}\right)$ with labeled ECM $(\triangle)$. The remaining ECM-bound platelet aggregates were subjected to a vigorous pipettation, resuspended in PPP, and incubated at $\mathrm{pH} 6.5$ with the labeled ECM (৯). Sulfate-labeled ECM was also incubated $\left(24 \mathrm{~h}, 37^{\circ} \mathrm{C}, \mathrm{pH} 6.5\right)$ with $\operatorname{PPP}(0)$ or $\operatorname{PRP}(\bullet)$ without a prior incubation with unlabeled ECM. ECM degradation products were analyzed by gel filtration on Sepharose 6B.

support the suggestion of Castellot et al. (5) that platelet heparitinase may be involved in the physiological and/or pathophysiological processes occurring during vascular endothelial lining injury and repair.

In addition to platelets, heparan sulfate endoglycosidase activity has been demonstrated in highly metastatic mouse melanoma $(9,17)$ and lymphoma (10) cell lines, and in activated normal cells of the immune system (24). Studies with these cell types suggested that the enzyme participates in the extravasation of blood-borne cells $(9,10,17)$. Although the low $M_{\mathrm{r}}$ sulfate-labeled fragments released from the ECM by the platelet heparitinase seem similar in size to those reported for the other cells $(9,10,17)$, it is still uncertain whether the above mentioned cell types share the same type of endoglycosidase activity. In fact, different substrate specificities were demonstrated for the platelet and B16 melanoma heparan sulfate-degrading enzymes. Whereas the platelet enzyme depolymerizes both heparan sulfate and heparin into small oligosaccharides $(1,3)$, the enzyme from B16 melanoma

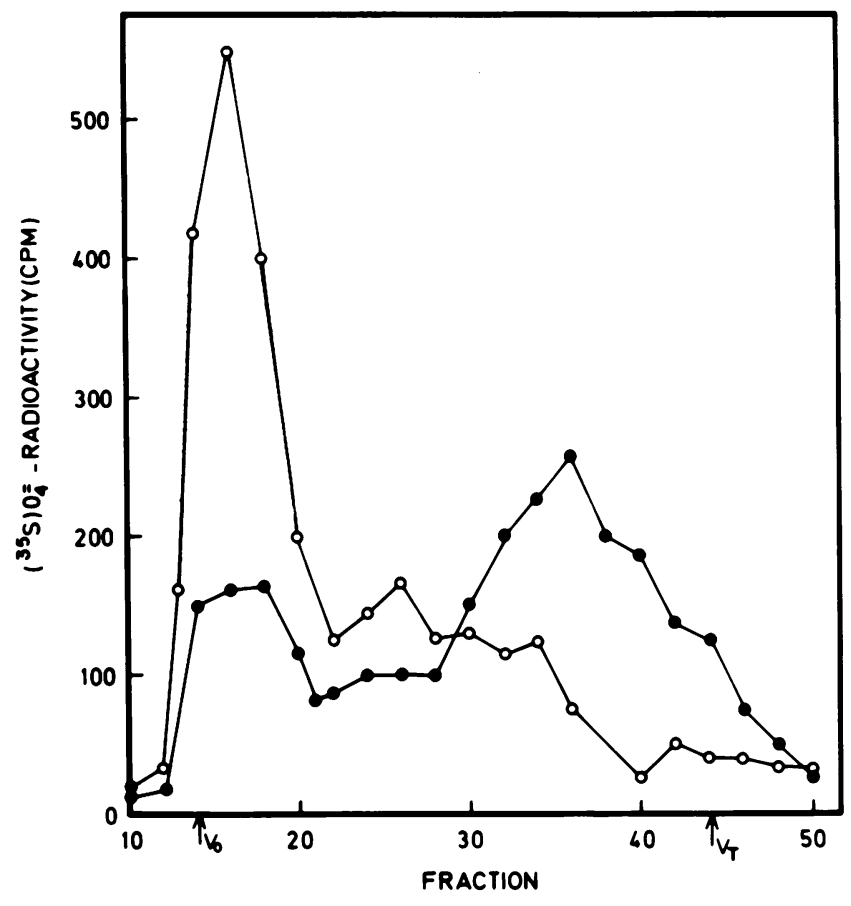

Figure 6. Further degradation by PRP of the high $M_{\mathrm{r}}$ sulfated proteoglycans produced by preincubation of ECM with PPP. PPP was incubated $\left(24 \mathrm{~h}, 37^{\circ} \mathrm{C}, \mathrm{pH} 7.4\right)$ with labeled ECM to release high $M_{\mathrm{r}}$ ${ }^{(35} \mathrm{S} \mathrm{O}_{4}^{=}$-labeled components eluted as peak I. This material was then collected and aliquots subjected to gel filtration after incubation with either PRP (•) or PPP (O).

was found to be very active against heparan sulfate, while heparin was not cleaved at significant rates (25). We have observed that the average $M_{\mathrm{r}}$ of ECM heparan sulfate degradation fragments was of a similar size (8,000-10,000 D) and almost no partially degraded chains, which eluted between peaks I and II, were produced regardless of the cell type and incubation conditions. Studies with B16 melanoma cells have demonstrated that heparan sulfate degradation fragments from subendothelial ECM were larger than those of heparan sulfate degradation products from other sources (25). It was suggested that because of its block type structure of low $N$-acetyl group content (heparin-like structure) (21), ECM heparan sulfate may have only a few linkages susceptible to the enzyme. If these linkages are similarly available for cleavage, then variation in enzyme concentration and incubation time may primarily effect the amount of released material and not so much the size of fragments.

Incubation of the ECM with PRP or with washed platelets at $\mathrm{pH}$ above 7.4 , as well as with PPP at both high and low $\mathrm{pH}$, released high $M_{\mathrm{r}}\left(\sim 10^{6} \mathrm{D}\right)\left({ }^{35} \mathrm{~S}\right) \mathrm{O}_{4}^{=}$-labeled components. Similar high $M_{\mathrm{r}}$ degradation products were released after a short-term exposure of the ECM to purified trypsin (17), or to a trypsin-like protease purified from high and low metastatic lymphoma sublines (Bar-Ner, M., M. Kramer, V. Schirrmacher, R. I. Michaeli, Z. Fuks, and I. Vlodavsky, submitted for 
publication). Although in the present study various protease inhibitors failed to inhibit this degradation activity, proteolysis may still be involved since it is conceivable that some of the plasma proteases were not sensitive to the specific protease inhibitors used. Addition of PRP to the high $M_{\mathrm{r}}$ material first released from the ECM by PPP yielded low $M_{\mathrm{r}}$ fragments eluted with the same $\mathrm{Kav}$ as those released upon direct incubation of the ECM with PRP. Therefore, it is suggested that degradation of proteoglycans in the ECM proceeds in a cascade sequence with the protease products providing adequate substrates for the platelet endoglycosidase activity. The contributory role of a proteolytic activity was recently demonstrated in the ESb lymphoma cell system where the addition of trypsin stimulated by 10-30-fold the heparitinase-mediated release of ECM heparan sulfate degradation products (Bar-Ner, M., M. Kramer, V. Schirrmacher, R. I. Michaeli, Z. Fuks, and I. Vlodavsky, submitted for publication). These results do not exclude the possibility of a direct attack on ECM-bound proteoglycans. Such degradation was observed upon incubation of ECM with a purified preparation of heparitinase from Flavobacterium heparinum. Degradation by this enzyme was also markedly increased in the presence of added trypsin (BarNer, M., M. Kramer, V. Schirrmacher, R. I. Michaeli, Z. Fuks, and I. Vlodavsky, submitted for publication).

We have previously shown that platelet interaction with the ECM is associated with the formation of platelet aggregates (6). We now report that under various experimental conditions (i.e., aspirinized platelets, washed platelets devoid of fibrinogen, pH 6.5), adhesion of platelets to the subendothelium, rather than aggregation, is sufficient for degradation of heparan sulfate. Aggregation of platelets induced by the ECM was associated with serotonin release but there was no significant release of heparitinase activity into the supernate fraction. In contrast, exposure of platelets to thrombin or platelet activation during clotting of whole blood resulted in a massive release of the enzyme to the serum. This release seemed indeed to be a result of platelet activation since it was inhibited by $\mathrm{PGI}_{2}$. The observation that platelet adherence is sufficient for the expression of platelet activation as detected by heparitinase activity is not unique since there are other adherence-related platelet functions. Using fluorescent antibodies, it has been shown that platelet factor IV is transferred from adherent platelets to subendothelial structures in the vessel wall (26). It has also been shown that blocking of platelet aggregation on deendothelialized surfaces of blood vessels did not inhibit the release of platelet-derived growth factor as demonstrated by the induction of proliferation of neointinimal smooth muscle cells (27).

The biological significance of the platelet heparitinase is not as yet fully understood. The observations that adherent platelets degrade heparan sulfate-containing proteoglycans in the subendothelial basal lamina and that heparan sulfate fragments released from the endothelial cell surface suppress smooth muscle cell proliferation (5) suggest that the enzyme is involved in the regulation of cell growth within injured vessels. The significance of these observations can be questioned in light of the low heparitinase activity observed at physiological $\mathrm{pH}$. It could well be, however, that the local $\mathrm{pH}$ found in areas of contact between platelets and the subendothelial ECM is somewhat lower and hence more appropriate for the enzyme. Also, a maximal activity over a broad $\mathrm{pH}$ range (5.5-7.5) was demonstrated by Oosta et al. (4) for a purified preparation of the platelet heparitinase using Sepharose-bound ${ }^{125} \mathrm{I}$-heparin as a substrate.

The data of the present study demonstrate that heparitinasemediated degradation of heparan sulfate in the subendothelium may occur, albeit to a low extent, even when an intact endothelial cell monolayer covers the subendothelial basement membrane. As visualized by scanning electron microscopy (unpublished observations), this degradation is in all likelihood initiated by adherence of either single or small aggregates of platelets to minor gaps between adjacent endothelial cells. In view of the reported correlation between the expression of heparitinase activity and the extravasation of blood-borne cells, it may well be that this observation is related to the mechanism of cell invasion through walls of small vessels and capillaries. Although exit of platelets through intact blood vessels has not been demonstrated, they may still participate in the extravasation of other cells. Due to their high affinity to exposed areas of the subendothelium, platelets may cause the initial damage to the integrity of the vascular intima by means of their heparitinase activity and thus produce the necessary preliminary conditions for extravasation of other cells. In fact, it has been suggested that platelets have a role in the sequestration, adherence, and penetration of tumor cells through the blood vessel endothelial cell barrier (28-31). Furthermore, a correlation was found between the ability of some tumor cells to aggregate platelets in vitro and their metastatic potential in vivo (30). Preliminary scanning electron microscopy and biochemical studies performed with our in vitro system suggest that both normal and malignant cells can recruit platelets and utilize their heparitinase activity to invade the endothelial cell layer and its underlying ECM. The possible involvement of the platelet heparitinase in the extravasation of blood-borne cells is supported by the antimetastatic effect of heparin and prostacyclin $(29,32)$, which in the present study were also shown to inhibit the activity and release of the enzyme.

\section{Acknowledgments}

The work was carried out in part at the A. Jurzykowski Hemostasis Laboratory of the Department of Hematology. The authors wish to thank Ms. D. Gurfel, Ms. R. Atzmon, and Ms. E. Hy-Am for their help with scanning electron microscopy and excellent technical assistance. We thank Ms. S. Berman for help in the preparation of this manuscript.

This work was supported by U. S. Public Health Service grant number CA 30289 awarded to Dr. Vlodavsky by the National Cancer Institute, Department of Health and Human Services; by a grant to Dr. Yahalom from the Joint Research Fund of the Hebrew University and Hadassah; and by a grant to Dr. Eldor from the Hoechst AG, Frankfurt. 


\section{References}

1. Wasteson, A., M. Höök, and B. Westermark. 1976. Demonstration of a platelet enzyme, degrading heparan sulphate. FEBS Lett. 64:218221.

2. Wasteson, A., B. Glimelius, C. Busch, B. Westermark, C. H. Heldin, and B. Norling. 1977. Effect of a platelet endoglycosidase on cell surface associated heparan sulphate of human cultured endothelial and glial cells. Thromb. Res. 11:309-321.

3. Oldberg, A., C. Heldin, A. Wasteson, C. Busch, and M. Höök. 1980. Characterization of a platelet endoglycosidase degrading heparinlike polysaccharides. Biochemistry. 19:5755-5762.

4. Oosta, G. M., L. V. Favreau, D. L. Beeler, and R. D. Rosenberg. 1982. Purification and properties of human platelet heparitinase. $J$. Biol. Chem. 257:11249-11255.

5. Castellot, J. J., L. V. Favreau, M. J. Karnovsky, and R. D. Rosenberg. 1982. Inhibition of vascular smooth muscle growth by endothelial cell-derived heparin. J. Biol. Chem. 257:11256-11260.

6. Vlodavsky, I., A. Eldor, E. Hy-Am, R. Atzmon, and Z. Fuks. 1982. Platelet interaction with the extracellular matrix produced by cultured endothelial cells: a model to study the thrombogenicity of isolated subendothelial basal lamina. Thromb. Res. 28:179-191.

7. Vlodavsky, I., G. M. Liu, and D. Gospodarowicz. 1980. Morphological appearance, growth behavior and migratory activity of human tumor cells maintained on extracellular matrix versus plastic. Cell. 19:607-616.

8. Gospodarowicz, D., I. Vlodavsky, and N. Savion. 1980. The extracellular matrix and the control of proliferation of vascular endothelial and vascular smooth muscle cells. J. Supramol. Struct. 13:339372.

9. Kramer, R. H., K. G. Vogel, and G. L. Nicolson. 1982. Solubilization and degradation of subendothelial matrix glycoproteins and proteoglycans by metastatic tumor cells. J. Biol. Chem. 257:26782686.

10. Vlodavsky, I., Z. Fuks, M. Bar-Ner, Y. Ariav, and V. Schirrmacher. 1983. Lymphoma cell mediated degradation of sulfated proteoglycans in the subendothelial extracellular matrix: relationship to tumor cell metastasis. Cancer Res. 43:2704-2711.

11. Hassell, J. R., P. G. Robey, H. J. Barrach, J. Wilczek, S. I. Rennard, and G. R. Martin. 1980. Isolation of a heparan sulfate containing proteoglycan from basement membrane. Proc. Natl. Acad. Sci. USA. 77:4494-4498.

12. Kefalides, N. A., R. Alper, and C. C. Clark. 1979. Biochemistry and metabolism of basement membranes. Int. Rev. Cytol. 61:167-228.

13. Gospodarowicz, D., H. Bialecki, and G. Greenburg. 1978. Purification of the fibroblast growth factor activity from bovine brain. J. Biol. Chem. 253:3736-3743.

14. Hawker, R. J., C. M. Hawker, and A. R. Wilkinson. 1980. Indium ("11'In)-labeled human platelets: optimal method. Clin. Sci. 58:243-248.

15. Gospodarowicz, D., J. Moran, D. Braun, and C. Birdwell. 1976. Clonal growth of bovine vascular endothelial cells: fibroblast growth factor as a survival agent. Proc. Natl. Acad. Sci. USA. 73:41204214.

16. Gospodarowicz, D., A. R. Mescher, and C. R. Birdwell. 1977. Stimulation of corneal endothelial cell proliferation in vitro by fibroblast and epidermal growth factors. Exp. Eye Res. 25:75-89.

17. Vlodavsky, I., Y. Ariav, R. Atzmon, and Z. Fuks. 1982. Tumor cell attachment to the vascular endothelium and subsequent degradation of the subendothelial extracellular matrix. Exp. Cell Res. 140:149150.

18. Wasteson, A. 1971. A method for the determination of the molecular weight and molecular weight distribution of chondroitin sulphate. J. Chromatogr. 59:87-97.

19. Roden, L., J. R. Baker, J. A. Citonelli, and M. B. Mathews. 1972. Isolation and characterization of connective tissue polysaccharides. Methods Enzymol. 28:73-140.

20. Lindahl, U., G. Backstrom, L. Jansson, and A. Hallen. 1973. Biosynthesis of heparin. II. Formation of sulfamine groups. J. Biol. Chem. 248:7234-7241.

21. Linker, A., and P. Hovingh. 1972. Heparinase and heparitinase from Flavobacteria. Methods Enzymol. 28:902-911.

22. Kaplan, K. L., M. J. Brockman, A. Chernoff, G. R. Lesnick, and M. Drilling. 1979. Platelet $\alpha$-granule proteins: studies on release and subcellular localization. Blood. 53:604-618.

23. Jones, P. A., and Y. A. De Clerck. 1982. Extracellular matrix destruction by invasive tumor cells. Cancer Metastasis Rev. 1:289317.

24. Savion, N., Z. Fuks, and I. Vlodavsky. 1984. T-lymphocytes and macrophage interaction with cultured vascular endothelial cells: attachment, invasion and subsequent degradation of the subendothelial extracellular matrix. J. Cell Physiol. 118:169-176.

25. Nakajima, M., T. Irimura, N. Di Ferrante, and G. L. Nicolson 1984. Metastatic melanoma cell heparanase. J. Biol. Chem. 259:22832290.

26. Goldberg, I. D., M. B. Sternerman, and R. I. Hardin. 1980 Vascular permeation of platelet factor 4 after endothelial injury. Science (Wash. DC). 209:611-612.

27. Packham, M. A., J. P. Cazenave, R. L. Kinlough-Rathbone, and F. Mustard. 1978. Drug effects on platelet adherence to collagen and damaged vessel walls. Adv. Exp. Med. Biol. 109:253-259.

28. Gasic, G. J., T. B. Gasic, N. Galanti, T. Johnson, and S. Murphy. 1973. Platelet-tumor cell interaction in mice. The role of platelets in the spread of malignant disease. Int. J. Cancer. 11:704718.

29. Karpatkin, S., and E. Pearlstein. 1981. Role of platelets in tumor cell metastasis. Ann. Intern. Med. 95:636-641.

30. Marcus, J. M., M. McGill, E. Bustida, A. Ordinas, and G. A. Jamieson. 1980. The interaction of platelets, tumor cells and vascular endothelium. J. Lab. Clin. Med. 96:1046-1053.

31. Warren, B. A., and O. Vales. 1972. The adhesion of thromboplastic tumor emboli to vessel walls in vivo. Br. J. Exp. Pathol. 53:301-313.

32. Honn, K. V., B. Cicone, and A. Skoff. 1981. Prostacyclin: a potent antimetastatic agent. Science (Wash. DC). 212:1270-1272. 